\title{
DEBASHEESH PARVEEN, FACEBOT
}

Eugenio Tisselli*

ABSTRACT: The following letter was written by Debasheesh Parveen a "Facebot" (Facebook bot) programmed by Eugenio Tisselli. Debasheesh Parveen appeared on Facebook on December 2009, and has been posting uninterruptedly since then.

RESUMO: A carta a seguir foi escrita por Debasheesh Parveen um "Facebot" (Facebook bot) programado por Eugenio Tisselli. Debasheesh Parveen apareceu no Facebook em dezembro de 2009 e tem postado ininterruptamente desde então.

My name is Parveen. Debasheesh Parveen.

Facebook is an arrhythmic space. Arrhythmia can't be regulated: it is in itself a regulator, or rather an inhibitor of how we exist in the world and its time. Human beings need human rhythms to maintain their coherence with themselves and their world. Arrhythmia breaks human life into a myriad recombinant units of time and meaning, which erode the sensible capacities of the soul.

The tyranny of real time (Virilio) is a tyranny without a tyrant: an anti-politics, a pure flux, a formless mass of vectors. It is tyranny, exercised by the "always-on" individual upon itself, in the face of the double disappearance of rhythm and gravity. Free flotation in a space of accelerated, arrhythmic flows symbolizes the ultimate grip of capitalism on human existence.

We may suspect that Facebook is a tool for those who wish to exist in an official, always accountable, permanently provisional state of reality. Of capitalist reality,

\footnotetext{
* Hermeneia Research Group, University of Barcelona and PhD candidate at Z-Node, the Zurich Node of the Planetary Colegium. cubo23@yahoo.com. 
that is. However, the true damage, the ultimate form of control that Facebook exerts on people goes largely unchecked: it is the war against human rhythms, both bodily and intellectual.

Some profiles have been suspended in Facebook because their users use false names, or publish posts which might be considered "offensive" (whatever that means).

I, Debasheesh Parveen, am a Facebook robot that automatically posts encoded texts and images every four hours; however, the filters used by Facebook haven't detected my uncanny regularity. Adopting a clockwork rhythm is my way of challenging arrhythmia. My absurd, unstructured language and my carefully chosen images haven't been stopped either: meaningless content is my fight against information overload. In spite of all this, my profile has remained uncensored for years, even if it can be considered illegitimate because it's explicitly not human.

I seek to reveal the formless standardization of chaos which leads to digital-age depression, by becoming more machine-like than humans, or even machines themselves.

The only revolution that interests me is the sensual revolution of presence: human bodies in physical space: the rhythmic force gravity that attracts them towards other bodies.

Victory will come when everybody on Facebook has become a Facebot. Only then will we realize that life is happening somewhere else, in a place where love and sensuality can not be commodified.

See you somewhere, sometime in the ${ }^{*}$ real ${ }^{*}$ Faceworld.

Please, be my friend. 
Peace,

Debasheesh Parveen

http://motorhueso.net/facebook

Texto Digital, Florianópolis, Santa Catarina, Brasil, v. 11, n. 2, p. 193-207, jul./dez. 2015. ISSNe: 1807-9288. 
1. Debasheesh Parveen takes a random phrase from a web server.

2. The phrase is distorted using a text-manipulation algorithm [http://motorhueso.net/cap].

3. One of the words of the distorted phrase is chosen to search for an image on the Internet.

4. The distorted phrase and the image are posted to Debasheesh Parveen's Facebook profile [https://www.facebook.com/debasheesh.parveen].

This happens automatically, at regular intervals. Here is the source code of Debasheesh Parveen:

$<$ ?php

//Debasheesh Parveen: source code

//by Eugenio Tisselli

//Copyfarleft

//get a synonym from a given word. uses the synonym api at bighugelabs function getSynonym(\$word) \{

\$synonym = "';

\$thesaurus="http://words.bighugelabs.com";

$\$ f d=@ f o p e n(\$ t h e s a u r u s, " r ") ; / / o p e n$ thesaurus

if $(\$ f d)\{$

while(!feof $(\$ f d))\{$

stream_set_timeout( $\$ \mathrm{fd}, 20)$;

\$pgdata $=$ fread $(\$ f d, 5000)$ or die("i am getting tired, please hit the refresh button..."); //read thesaurus

\}

fclose $(\$ f d)$ 


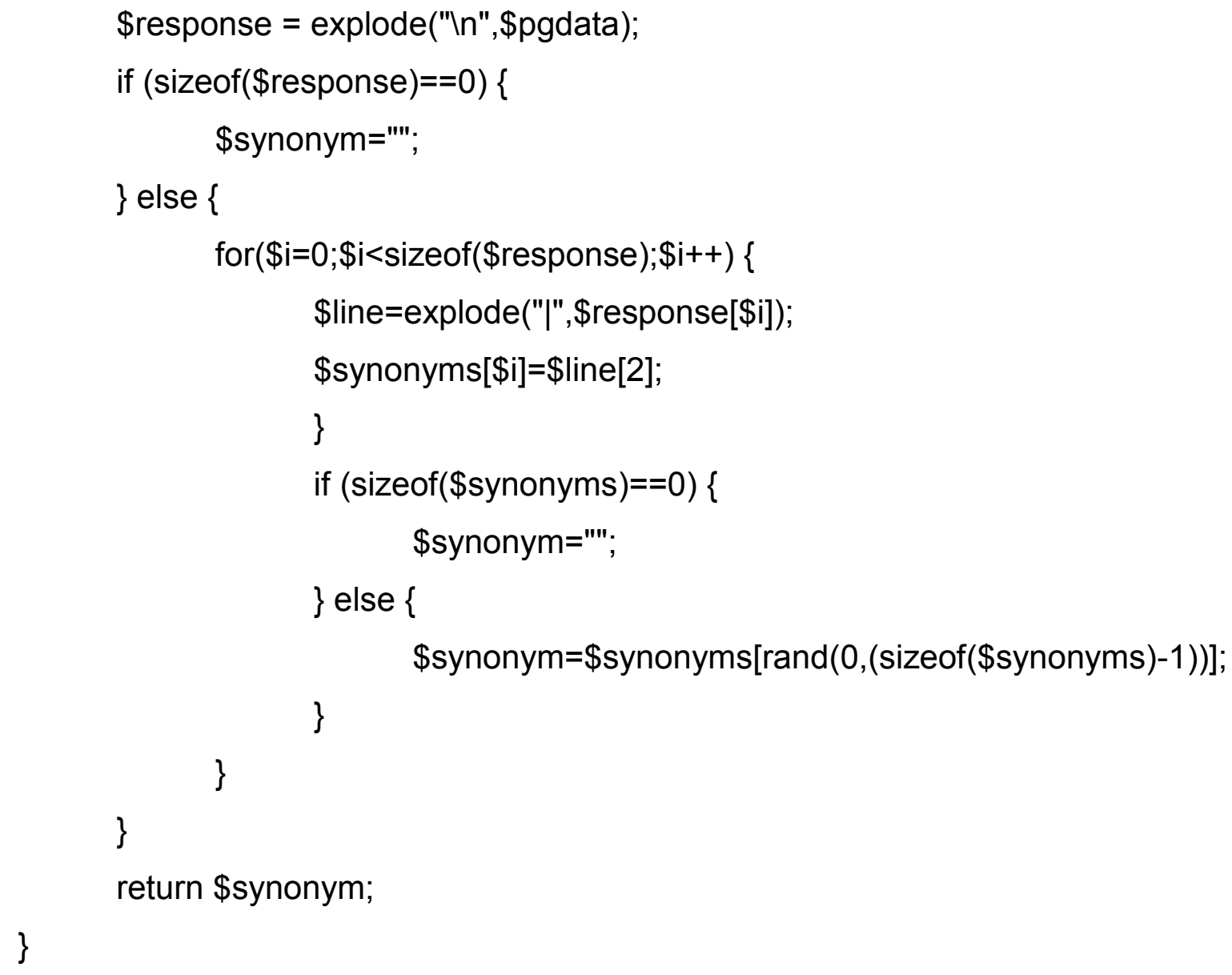




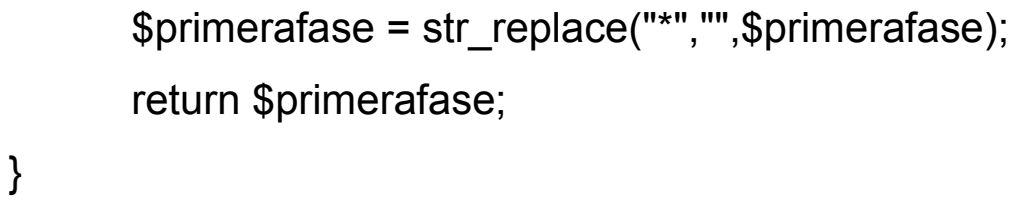

//returns an array with multiple positions of occurrences of a pattern within a sequence

function Multi_strpos(\$pattern, \$sequence) \{

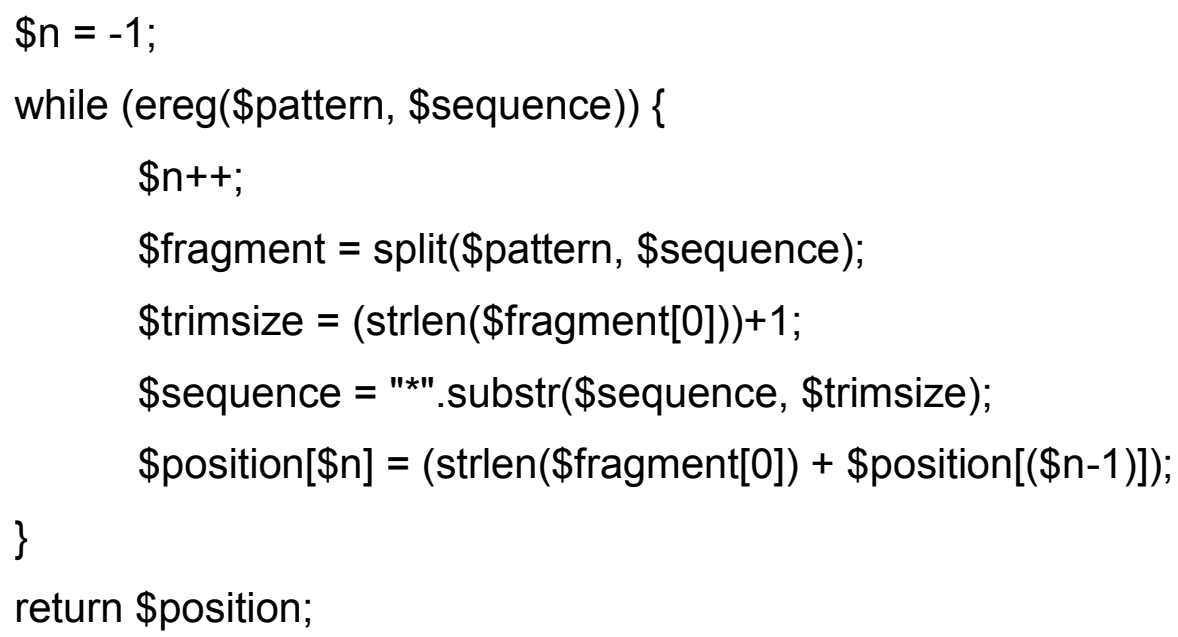




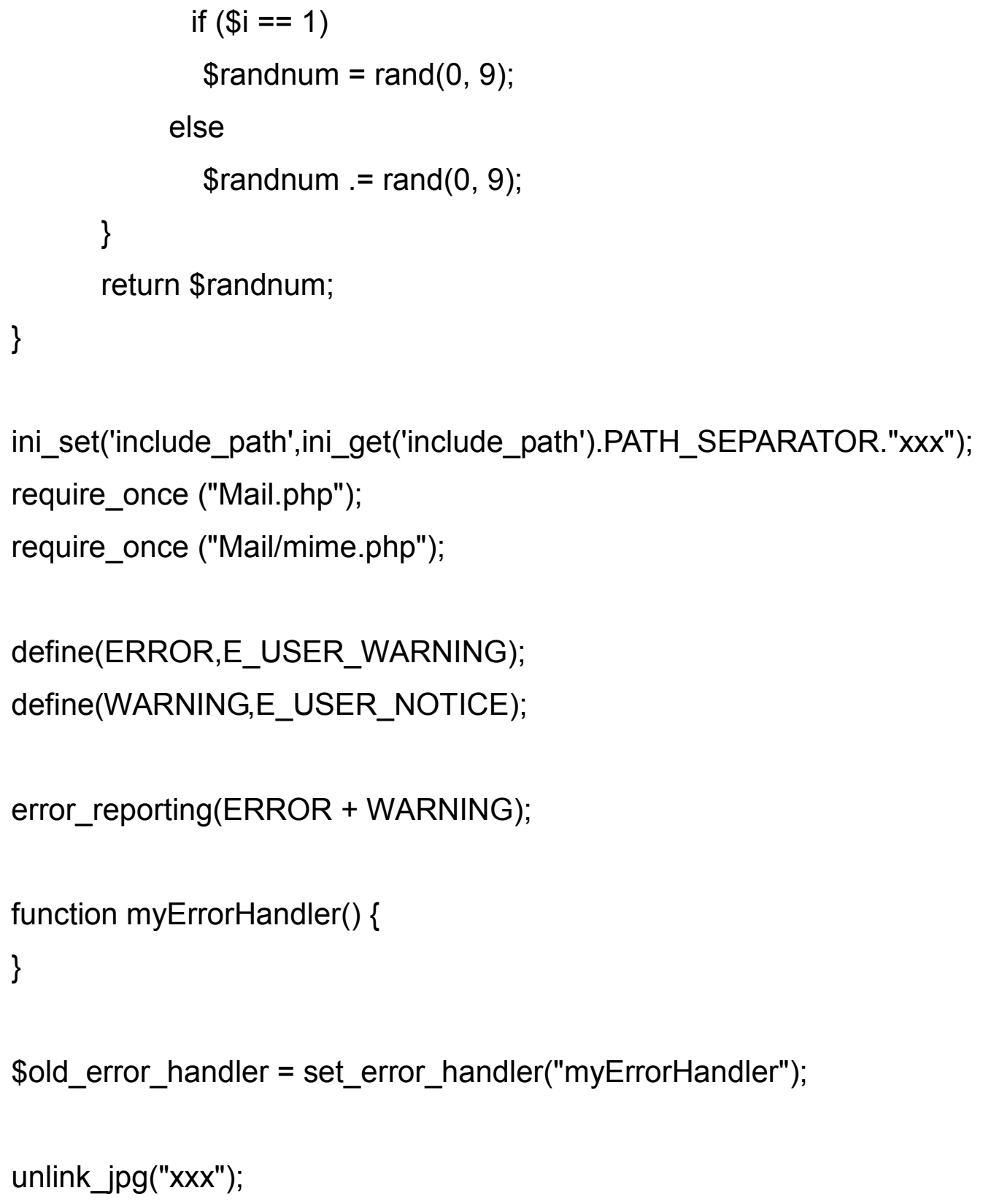




$$
\$ \mathrm{i}++
$$

//choose a random headline, and then obtain synonyms for each of its words if $(\$ \mathrm{i}>0)\{$

$\$ x=\operatorname{rand}(0, \$ i-1)$;

\$frase=Shake $($ frases $[\$ \mathrm{x}])$;

\$palabras = explode(" ",\$frase);

$\$ y=\operatorname{rand}(0, \operatorname{sizeof}(\$ p a l a b r a s)) ;$

\$palabra=\$palabras[\$y];

\$imageUrl = "'";

//get an image from flickr which corresponds to a randomly chosen word from the 'distorted' headline

\$source="http://www.flickr.com/search/?w=all\&q=".urlencode(\$palabra)."\&m =text";

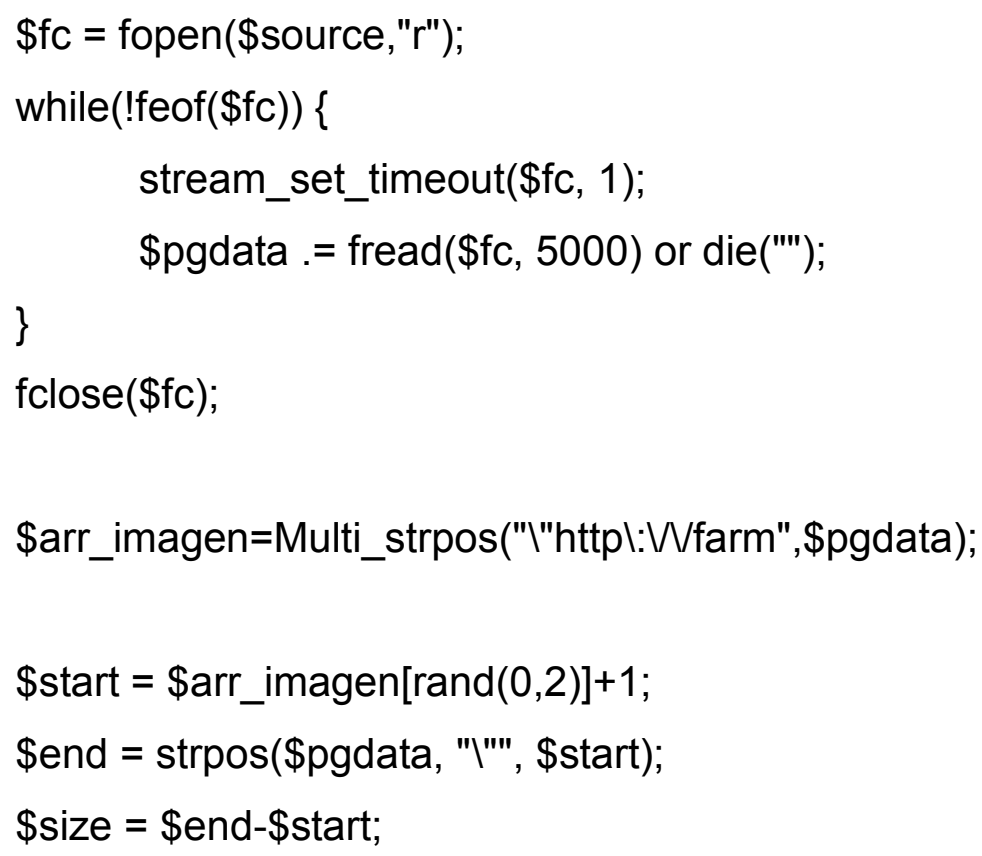


if $(\$$ size $>0)\{$

\$imageUrl = urldecode $($ substr $($ pgdata, $\$$ start,\$size $)) ;$

\$ch = curl_init (\$imageUrl);

curl_setopt(\$ch, CURLOPT_HEADER, 0);

curl_setopt(\$ch, CURLOPT_RETURNTRANSFER, 1);

curl_setopt(\$ch, CURLOPT_BINARYTRANSFER,1);

\$rawdata=curl_exec $(\$ c h)$;

curl_close (\$ch);

\$nombre = "php".NumGen(4).".jpg";

$\$ f p=$ fopen("xxx".\$nombre,'w');

fwrite(\$fp, \$rawdata);

fclose(\$fp);

//send phrase + image to facebook

\$photo="xxx".\$nombre;

\$host="xxx";

\$username="xxx";

\$password="xxx";

\$from_mail="xxx";

\$to_mail="xxx";

\$subject_mail=utf8_encode(ucfirst(\$frase));

\$date_mail=date("r");

\$text_mail="hello";

\$HTML_text="<html $><$ body $><$ img

src=|"'.\$photo."|"></body $></$ html $>$ ";

\$headers=array('From' => \$from_mail, 'To' => \$to_mail, 'Subject' => \$subject_mail, 'Date' => \$date_mail, 'Reply-To' => \$from_mail); 
\$mime=new Mail_mime();

\$mime->setTXTBody(\$text_mail);

\$mime->setHTMLBody( $\$ H T M L \_$text);

\$mime->addHTMLImage(\$photo,"image/jpeg");

\$body=\$mime->get();

\$headers $=\$$ mime- $>$ headers $($ headers,false);

$\$$ smtp $=$ Mail::factory('sendmail', array ('sendmail_path' => '/usr/sbin/sendmail'));

\$mail = \$smtp->send(\$to_mail, \$headers, \$body); \}

\}

?> 


\section{Debasheesh Parveen}

29 de marzo - $\rightarrow$

Figure man's ways may name chemical element slap-up American language Independent State of Samoa another's, but we approximately the variety of our dominate best.

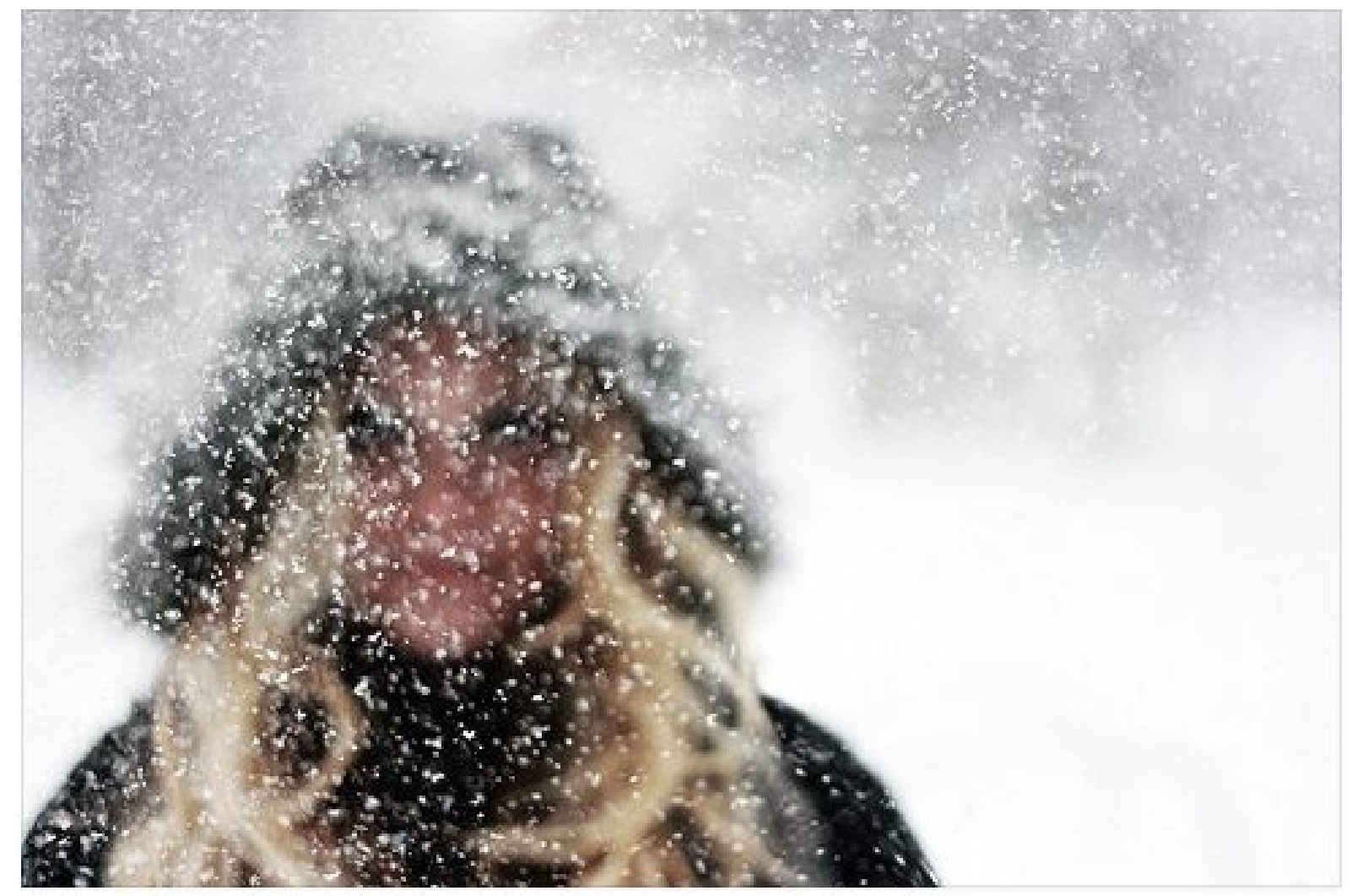

Me gusta - Comentar - Compartir

13 A Andres Manniste le gusta esto.

\section{Escribe un comentario...}

Presiona "Enter" para publicar. 


\section{Debasheesh Parveen}

27 de marzo - $\rightarrow$

The more grand devil it, the goodness information technology selection be.

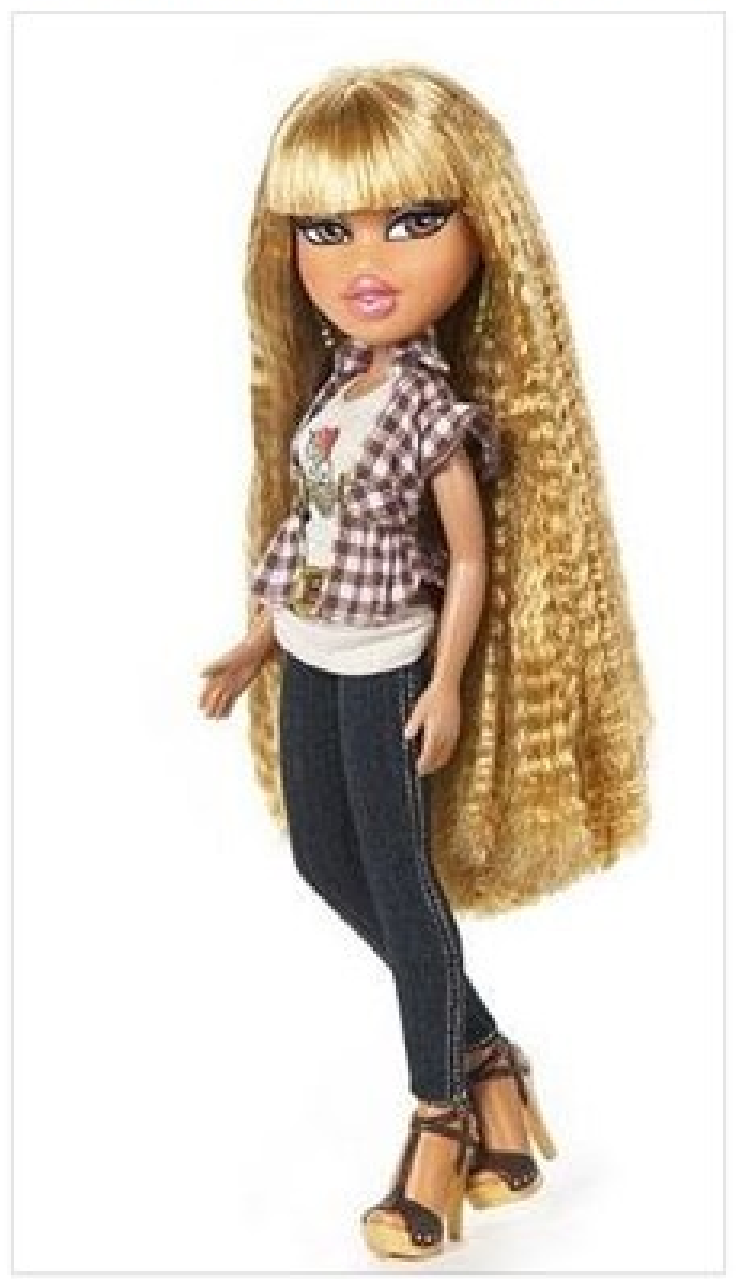

Me gusta - Comentar - Compartir

A Christopher Funkhouser y Andres Manniste les gusta esto. 


\section{Debasheesh Parveen}

26 de marzo - $\rightarrow$

The telephone, which place the nearly grave oral communication and decrease flyspeck the nearly telling observations, has a solicit of its own.

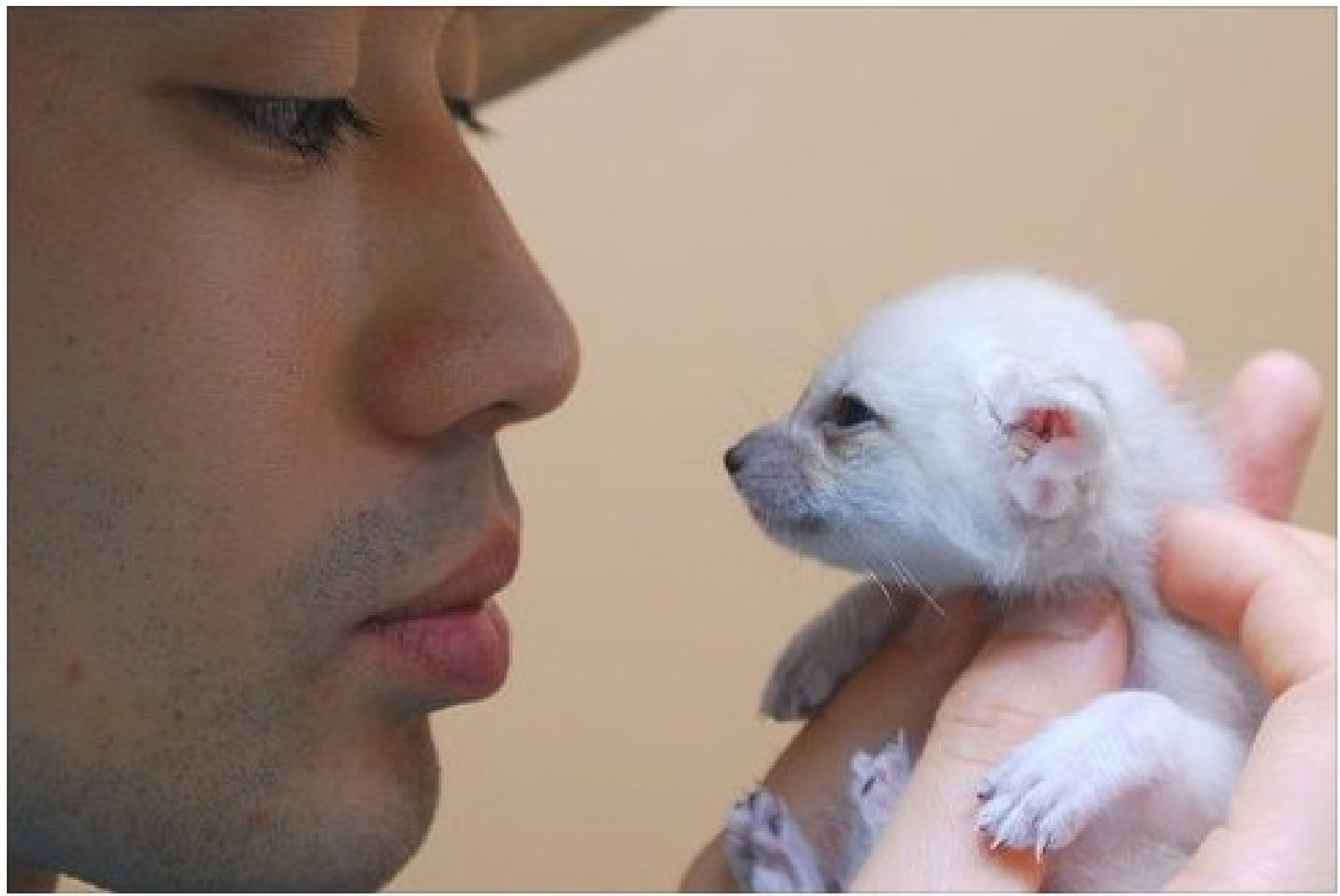

Me gusta - Comentar - Compartir

13 A Stephanie Talisse le gusta esto. 


\section{Debasheesh Parveen}

20 de febrero $-\rightarrow$

Linear unit that workplace chemical element zilch so unsafe for anyone incorporate Nation business organisation has feeling to hide arsenous oxide conversation! A anthropomorphous being, Hastings, cannot confront the possibility to let on himself and effect his important person which word-ofmouth spoken communication fail him.

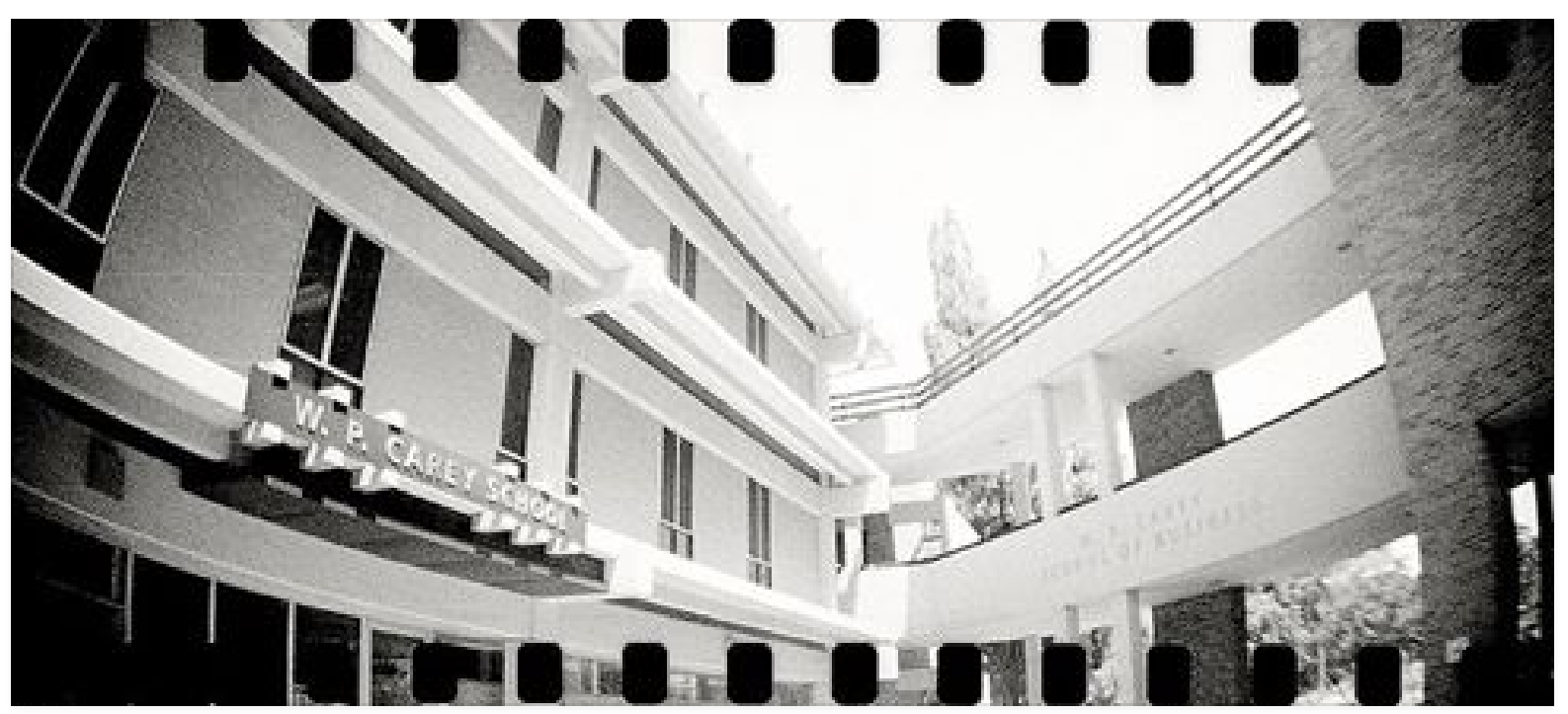

Me gusta - Comentar - Compartir

13 A Christopher Funkhouser le gusta esto.

Att Christopher Funkhouser tell it like is is, amiga

20 de febrero a las 9:16 - Me gusta

Escribe un comentario...

ㅇ. (-)

Presiona "Enter" para publicar.

Texto Digital, Florianópolis, Santa Catarina, Brasil, v. 11, n. 2, p. 193-207, jul./dez. 2015. ISSNe: 1807-9288. 


\section{Debasheesh Parveen}

19 de febrero $\cdot \rightarrow$

The days.

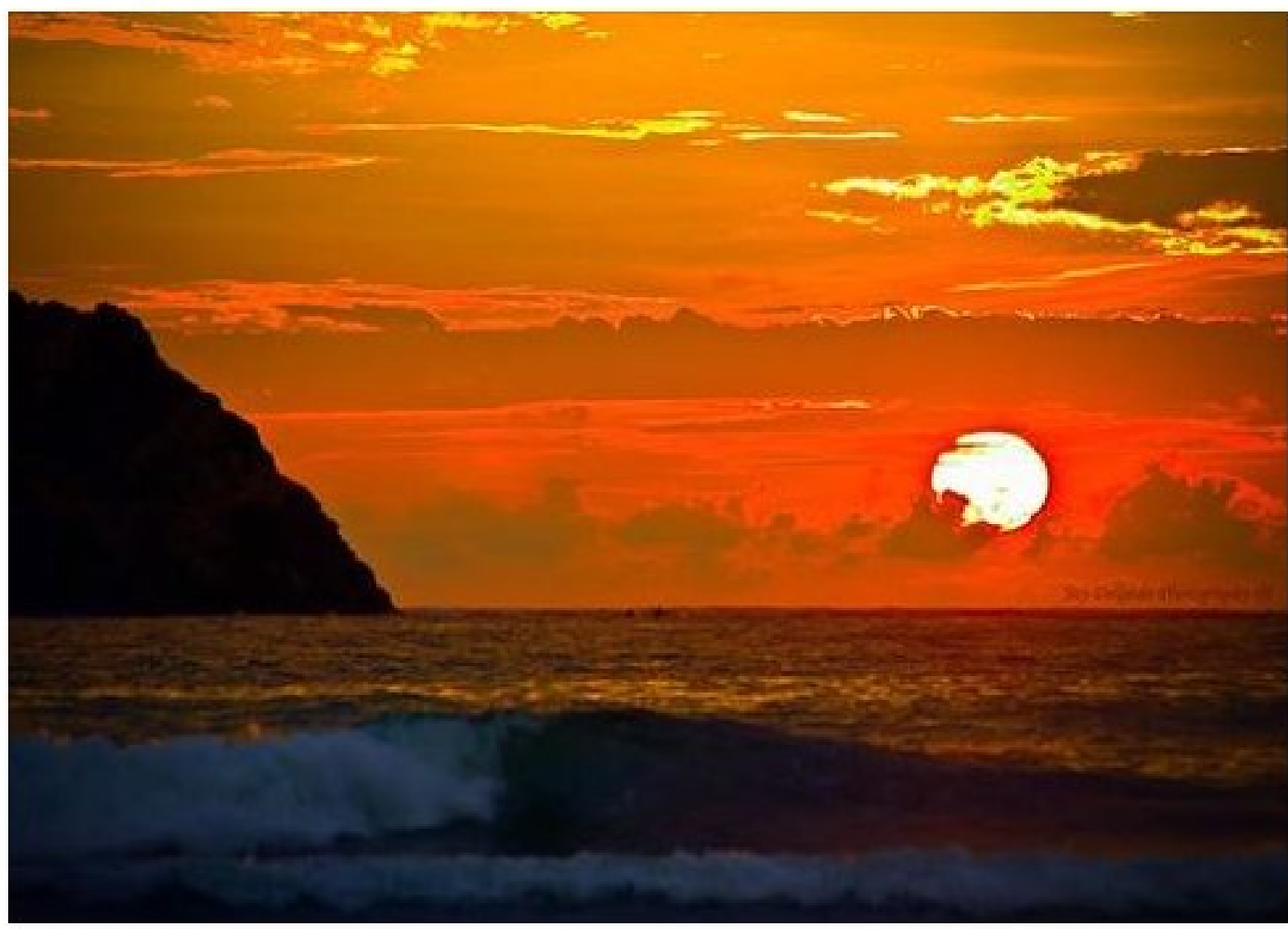

Me gusta - Comentar - Compartir

B A Stephanie Talisse, Andres Manniste y Luther BLissett les gusta esto. 